\title{
ANÁLISE DE ASSIMETRIA NA TRANSMISSÃO DE PREÇOS POR MEIO DE MODELOS VEC: APLICAÇÃO À CADEIA PRODUTIVA DE CARNE BOVINA
}

\author{
Helena loiola Persona* \\ Adelson Martins Figueiredo ${ }^{\dagger}$ \\ Danilo R. D. Aguiar $\ddagger$
}

\begin{abstract}
Resumo
Este artigo visa analisar a transmissão de preços e as margens de comercialização entre os segmentos da cadeia produtiva de carne bovina, buscando evidência de possível exercício de poder de mercado. Foram estimados dois modelos Vetoriais de Correção de Erros com base no enfoque de Houck. Os resultados indicam simetria nas relações de preços entre atacado e varejo e assimetria entre atacado e produtor. Assim, há alguma evidência de possível exercício de poder de mercado apenas de jusante a montante (do atacado para o produtor). Isto pode ser explicado pelas diferenças na estrutura de mercado, já que varejo e atacado são oligopólios, diferentemente dos produtores.
\end{abstract}

Palavras-chave: transmissão de preços, séries temporais, carne bovina, poder de mercado

\begin{abstract}
This paper aimed to analyze the price transmission and marketing margins among the segments of beef production chain (farm, wholesale and retail), looking for evidence of possible exercise of market power. Two Vector Error Correction models were estimated based on Houck's framework. The results indicate symmetry in price transmission between wholesale and retail and price asymmetry between wholesale and producer. Thus, there is some evidence of the possible exercise of market power only from downstream to upstream (from wholesale to producer). This may be explained by differences in market structure, as retail and wholesale are oligopolies, unlike producers.
\end{abstract}

Keywords: price transmission, time series, beef, market power JEL classification: L11, C22.

DOI: http://dx.doi .org/10.11606/1980-5330/ea131211

\footnotetext{
${ }^{*}$ Doutoranda em Economia pela Unicamp e Pesquisadora do Grupo Economia Aplicada pela UFSCar. E-mail: helenaloiola@gmail.com

† Professor Associado do Departamento de Economia da UFSCar. E-mail: adelson@ufscar.br

‡ Professor Titular do Departamento de Economia da UFSCar. E-mail: danilo@ufscar.br
} 


\section{Introdução}

A cadeia agroindustrial da carne bovina constitui-se em um dos principais setores do agronegócio brasileiro no cenário mundial. Com quase $200 \mathrm{mi}-$ lhões de cabeças de gado, o Brasil possui o segundo maior rebanho efetivo do mundo, tendo assumido, desde 2004, a liderança nas exportações mundiais de carne bovina, com um market share de cerca de $20 \%$ e vendas para mais de 180 países (Brasil 2014). Apesar da sua pujança no mercado externo, o mercado interno ainda é o principal destino da produção de carne bovina, sendo que em 2013 o consumo per capita de carne bovina por parte dos brasileiros chegou a 37,4 kg (Brasil 2014). Ademais, projeções para o consumo de carne bovina no Brasil até 2024/2025 indicam uma taxa de crescimento de 1,5\% ao ano (Brasil 2015).

Ao longo das últimas décadas, o mercado doméstico de carne bovina tem passado por grandes mudanças no Brasil, devido a maiores exigências por parte de alguns segmentos de consumidores e à crescente importância dos super e hipermercados na distribuição do produto. Adicionalmente, tem havido expressiva concentração de mercado em nível de frigoríficos, com consequente formação de oligopsônios na compra de boi gordo para o abate, e oligopólios na venda de carne, conforme atestam Rodovalho (2010) e Moita \& Goloni (2010). Essas mudanças na estrutura do setor geram preocupações sobre a possibilidade de exercício de poder de mercado na cadeia produtiva de pecuária de corte, com efeitos nocivos a pecuaristas, consumidores e outros agentes de comercialização, o que torna relevante se examinar empiricamente as relações entre os vários níveis da cadeira produtiva. Uma das formas de se identificar a presença de poder de mercado parte da estimação de funções de custos, na linha da New Empirical Industrial Organization, conforme fez Urso (2007). Outro procedimento que vem sendo utilizado para buscar indícios de poder de mercado é a análise da assimetria na transmissão de preços (Aguiar \& Santana 2002, Aguiar \& Figueiredo 2011, Aguiar 2012, Santos et al. 2015). Segundo este enfoque, a transmissão mais intensa e/ou, mais rápida de acréscimos de preços pode ser evidência de exercício de poder de mercado.

Neste contexto, a análise da presença de assimetria na transmissão de preços entre os vários níveis de comercialização da cadeia produtiva de pecuária de corte poderia identificar evidências de uso de poder de mercado neste setor, fortalecendo argumentos de determinados setores em seus processos de negociação e embasando políticas de regulação e de controle de concentração de mercado por parte do governo e suas autarquias. Embora Aguiar \& Figueiredo (2011) já tenha identificado a presença de assimetria para o setor de carne bovina, entre outros, estes autores utilizaram o procedimento de Houck (1977), o qual tem sido criticado por alguns autores por não dar a devida atenção às propriedades das séries temporais no tratamento dos dados (Capps-Jr \& Sherwell 2007). Em função disso, alguns autores têm usado o modelo de correção de erro assimétrico (MCEA) proposto por Cramon-Taubadel (1998), ou têm estimado ambos os modelos para comparar seus resultados (Capps-Jr \& Sherwell 2007). A questão que fica, portanto, é se os resultados encontrados por Aguiar \& Figueiredo (2011) seriam confirmados por meio do modelo de correção de erro assimétrico.

Dessa forma, este artigo tem como objetivo analisar a transmissão de preços e as margens de comercialização entre os segmentos da cadeia produtiva de carne bovina, buscando evidência de possibilidades de exercício de poder 
de mercado via abordagem econométrica de vetores de correção de erros. Em razão da disponibilidade de dados, a análise empírica utiliza preços referentes ao Estado de São Paulo. A hipótese, com base na evidência existente na literatura e nas condições estruturais do setor, é de que os acréscimos de preços sejam transmitidos mais intensamente do que os decréscimos, tanto por parte dos atacadistas quanto por parte dos varejistas, os dois segmentos mais concentrados.

Este artigo contribui para a ciência econômica por desenvolver um modelo semelhante ao de Capps-Jr \& Sherwell (2007), mas que se aplica às relações entre três níveis de mercado. Ademais, contribui para a identificação e o acompanhamento de possível exercício de poder de mercado na cadeira produtiva de pecuária de corte do Brasil, uma questão que tem gerado grandes preocupações tanto para os agentes deste mercado como para o poder público. Capps-Jr \& Sherwell (2007) analisam a transmissão de preço no mercado de leite norte-americano entre dois níveis da cadeia produtiva, produtor e varejo, porém para analisar a cadeia produtiva da pecuária bovina no Brasil é importante fazer a separação entre os três níveis de mercado - produtor, atacado e varejo - dada a importância do atacado, ou do setor frigorífico. Dessa forma, esta pesquisa contribui tanto metodologicamente quanto para a identificação empírica de possibilidade de exercício de poder de mercado na cadeia produtiva de pecuária de corte brasileira. Em relação a este último ponto, embora o senso comum sugira que os pecuaristas estejam em desvantagem em relação aos demais níveis de comercialização em decorrência das estruturas de mercado vigentes nesses níveis, considera-se que a identificação empírica de possibilidade de exercício do poder de mercado é essencial para justificar eventuais ações do poder público ou para motivar estratégias de comercialização dos pecuaristas.

O artigo apresenta na seção seguinte a caracterização da estrutura da cadeia produtiva da pecuária bovina no Brasil, destacando-se evidências de poder de mercado do setor atacadista e varejista nessa cadeia de produção. As seções subsequentes apresentam a metodologia, os resultados e as conclusões e considerações finais que podem ser extraídas da análise da transmissão de preço no mercado de carne bovina.

\section{A Cadeia Produtiva da Pecuária Bovina no Brasil}

A cadeia da carne bovina engloba mais agentes do que apenas os produtores, os frigoríficos e os varejistas. Além destes, há também a indústria de insumos, que fornece equipamentos agrícolas, vacinas, sal mineral e ração animal, e a indústria de transformação que produz roupas, sapatos, sabonetes, adubos, entre outros produtos derivados da pecuária bovina.

Os produtores realizam a cria de bezerros, a recria de bois magros e a engorda. Em 2017, 224,6 mil fazendas com 50 cabeças ou mais venderam bovinos para abate no Brasil (IBGE 2018). Os frigoríficos compram os bois dos produtores e fazem o abate, a limpeza, a desossa, a embalagem e a venda do animal. Segundo Moita \& Goloni (2010), eram 210 frigoríficos no final dos anos 1970, número que se reduziu para 80 estabelecimentos em 2009, o que mostra uma concentração de mercado no setor de processamento da cadeia da pecuária bovina. Quanto ao varejo, os supermercados e açougues preparam a carne para a venda ao consumidor final. 
A cadeia da pecuária de corte em 2007 apresentava um faturamento de $\mathrm{R} \$ 280$ bilhões, valor que atingiu R $\$ 414$ bilhões em 2013, representando um aumento de 5,17\% ao ano. Em 2017 esse faturamento foi de R\$ 523 bilhões, sendo que o faturamento da produção foi de $\mathrm{R} \$ 96,04$ bilhões, o dos frigoríficos de R\$124,68 bilhões, e o do varejo de R\$175,93 bilhões, segundo dados da ABIEC (2018). Com isso, o varejo passou a ter a maior participação no faturamento da cadeia, seguido pelos frigoríficos e pelos produtores. Na Figura 1 mostra-se a evolução da participação desses agentes no faturamento da cadeia entre 2014 e 2017.

Figura 1: Evolução da participação de cada elo de produção no faturamento da cadeia produtiva de pecuária de corte entre 2014 e 2017 (em $\%)$.

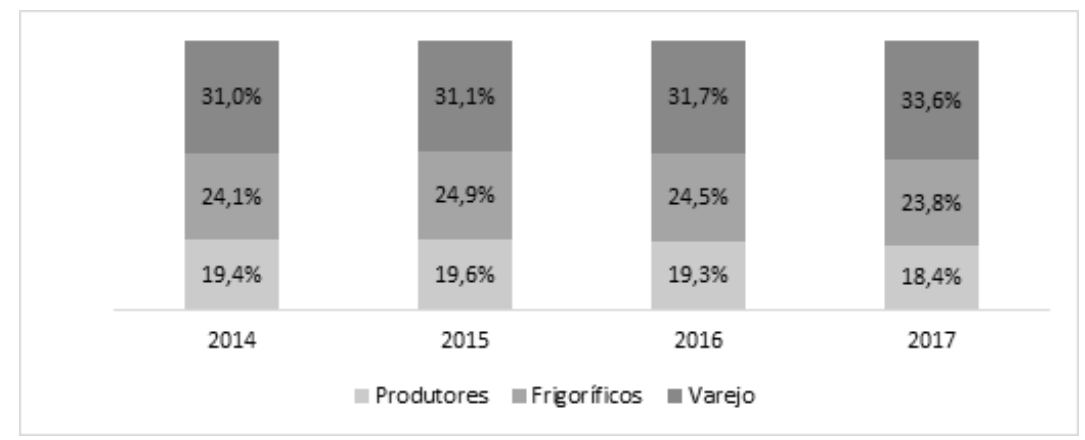

Fonte: ABIEC (2018).

Nas últimas décadas, a cadeia produtiva de carnes tem se tornado mais eficiente no Brasil, à medida que foram implantadas novas tecnologias, como a inseminação artificial, a transferência de embriões e a redução do tempo do abate. Essas medidas melhoraram a qualidade da carne e garantiram a oferta mais constante para o consumidor final Moita \& Goloni (2010). A reestruturação desse mercado ocorreu em paralelo à mudança de estratégia por parte dos frigoríficos, que passaram a ter grandes plantas estrategicamente localizadas nas regiões de maior produção de carne (ABIEC 2018).

Essa reestruturação levou a uma maior concentração de mercado entre as empresas que realizam o abate de animais no Brasil, como já destacado. Considerando somente o abate fiscalizado com inspeção federal, a participação de apenas quatro grupos - JBS, Marfrig, Minerva e BRF - no abate total de bovinos no Brasil saltou de 27,8\%, em 2007, para 52\%, em 2013, e continua aumentando a cada ano, sendo que a JBS apresentou as maiores participações no total de abate no período, mais do que dobrando a taxa entre 2007 - de 14,4\% - e 2013 - de 32,56\% (Carvalho \& Zen 2017).

Esses resultados decorrem das estratégias desses grupos adotadas nos últimos anos. A JBS buscou não apenas consolidar a globalização da empresa com aquisições de diversas empresas estrangeiras ${ }^{1}$, mas também expandir e diversificar geograficamente suas unidades de produção e distribuição no mercado

\footnotetext{
${ }^{1}$ Desde 2008 a JBS vêm adquirindo empresas estrangeiras como a National Beef Packing Company (EUA); a Smithfield Beef Group (EUA); o Grupo Tasman (Austrália); a Pilgrims' Pride; a Tatiara (Austrália); Rockdale Beef (Austrália); o Grupo Toledo (Belgica); o McElhaney Family Farm (empresa de confinamento nos EUA); o Grupo Primo Smallgoods (Austrália - líder em produtos preparados à base de carne); a divisão de suínos da Cargill nos EUA. (JBS 2018)
} 
nacional. No mercado nacional, a JBS adquiriu a Swift \& Company, o que permitiu a atuação da empresa no varejo, e 50\% da INALCA; houve também uma fusão com a Bertin, segunda maior empresa de carne bovina no Brasil no formato holding, e uma integração com a Vigor a partir dessa fusão. Além disso, houve a aquisição da Seara, da Zenda e da Massa Leve, em 2013 (JBS 2018). A Marfrig também adquiriu algumas empresas internacionais ${ }^{2}$ e algumas empresas nacionais, como a Ampeno, do Rio Grande do Sul, a Carroll's Food do Brasil, a Moinhos Cruzeiro do Sul Ltda e a DaGranja Agroindustrial Ltda, além de ter adquirido $51 \%$ da Zenda e unidades de proteína da Seara que depois foram vendidas para a JBS (JBS 2018, Marfrig 2018). A Minerva também expandiu sua participação no mercado nacional adquirindo plantas de frigoríficos em Campina Verde (MG) e as operações de abate e desossa da BRFoods em Várzea Grande e Mirassol D’Oeste (MT) (Minerva 2018).

Dentro desse contexto, pode-se dizer que a indústria de carnes no Brasil se estrutura como um oligopsônio: muitos ofertantes (pecuaristas) e poucos demandantes (frigoríficos). Mas vale destacar que a negociação entre os produtores e os frigoríficos mudou muito desde a década de 2000. Estratégias buscado maior estabilidade de preços em prazos maiores aumentaram sua participação em relação àquelas negociadas no mercado spot, ou mercado físico, caracterizado pela troca do animal por dinheiro. Entre essas, os contratos a termo, contratos de longo prazo e integração vertical para trás, passaram a coexistir com o tradicional mercado spot (Carvalho \& Zen 2017).

As alternativas para os produtores fixarem os preços são o mercado a termo, o mercado futuro e o mercado de opções. O mercado a termo consiste na negociação de um contrato entre os produtores e frigoríficos que permite préestabelecer uma data futura e um preço, com o pagamento a vista ou a prazo. Dessa forma, o produtor não fica exposto aos ajustes diários e os custos do processo são do frigorífico; por outro lado, o ganho fica limitado ao contrato fixado. O mercado futuro é muito semelhante ao mercado a termo, só que há maior padronização e os contratos são negociados somente em bolsa e o produtor ou o frigorífico operam os contratos por meio de uma corretora. Já o mercado de opções é semelhante ao mercado futuro, mas permite que o investidor não exerça sua opção caso encontre condição mais vantajosa no mercado físico (Carvalho \& Zen 2017).

Em relação à estrutura de mercado e suas implicações, poucos estudos analisaram o poder de mercado na pecuária bovina no Brasil, entre eles Urso (2007) e Moita \& Goloni (2010), sendo que ambos utilizaram a estimação das curvas de demanda e oferta segundo o enfoque da New Empirical Industrial Organization (NEIO). O método proposto para identificação de possível exercício de poder de mercado neste artigo difere dos estudos citados e se baseia na análise da transmissão de preços entre os elos da cadeia produtiva da carne bovina, o que permite o cálculo das elasticidades de transmissão de preços sem precisar da estimação de uma função de custo agregada. O exercício de poder de mercado ${ }^{3}$ ocorre quando uma empresa (ou um grupo de empresas) é ca-

\footnotetext{
${ }^{2}$ Entre elas a Quickfood (líder argentina em produtos industrializados), a Estancias del Sur (Argentina), a Moy Park (maior produtora de aves da Irlanda do Norte, que depois foi vendida para a JBS), a CDB Meats (importadora e distribuidora de alimentos no Reino Unido) e a Keystone Foods (uma das maiores fornecedoras globais de alimentos para redes de restaurante e serviço rápido de alimentação, atuante na América do Norte, Ásia e Oceania). (Marfrig 2018)

${ }^{3}$ Poder de mercado pode ser também definido como a habilidade das firmas em manterem seus preços acima do custo marginal para obter lucro econômico (ver mais detalhes em Aguiar
} 
paz de manter seus preços sistematicamente acima do nível competitivo sem com isso perder seus clientes (CADE 2007). O poder de mercado vêm sendo apontado por diversos estudos como uma das causas da existência de assimetrias na transmissão de preços entre os segmentos de uma cadeia produtiva, tais como Meyer \& Cramon-Taubadel (2004), Cramon-Taubadel \& Fahlbusch (1994) e Kinnucan \& Foker (1987). Visto que a cadeia produtiva da carne bovina no Brasil é oligopolizada, principalmente por parte dos frigoríficos, o exame da transmissão de preços entre os segmentos dessa cadeia se justifica como método de identificação desse possível exercício de poder de mercado. A próxima seção discute a metodologia proposta por este artigo.

\section{Metodologia}

\subsection{Referencial analítico}

As análises da assimetria na transmissão de preços costumam ser apresentadas partir do modelo de Houck (1977), que pode ser representado como:

$$
\Delta P_{v t}=\alpha_{0}+\sum_{i=0}^{M_{1}} \alpha_{1 i} \Delta P_{p t-i}^{+}+\sum_{i=0}^{M_{2}} \alpha_{2 i} \Delta P_{p t-i}^{-}+\varepsilon_{t}
$$

onde $P_{v t}$ e $P_{p t}$ são os preços de um produto no varejo e em nível de produtor, respectivamente, para $t=1,2, \ldots, T$. $\Delta$ é o operador de primeira diferença, $\Delta P_{p t-i}^{+}=P_{p t}-P_{p t-1}$, se $P_{p t}>P_{p t-1}$ e 0 caso contrário, e $\Delta P_{p t-i}^{-}=P_{p t}-P_{p t-1}$, se $P_{p t}<P_{p t-1}$ e 0 caso contrário. O coeficiente $\alpha_{1 i}$ representa o impacto do aumento dos preços do produtor sobre os preços no varejo, e $\alpha_{2 i}$ representa o impacto da queda do preço do produtor sobre o preço no varejo. M1 e M2 representam a duração dos atrasos no repasse dos aumentos e das quedas do preço do produtor, respectivamente. A hipótese de assimetria na transmissão de preços pode ser testada estatisticamente por um teste $t$ ou pelo teste $F$, cuja hipótese nula é:

$$
H_{0}: \sum_{i=0}^{M 1} \alpha_{1 i}=\sum_{i=0}^{M 2} \alpha_{2 i}
$$

A não rejeição de $H_{0}$ é evidência de simetria na transmissão de preço entre produtor e varejo. Caso haja rejeição de $H_{0}$, é possível inferir assimetria na transmissão de preço.

Vários estudos nacionais e internacionais utilizaram este modelo e suas aproximações para avaliar ajustes assimétricos de preços para diferentes níveis de um mercado. Carman \& Sexton (2005), Lass (2005), e Azevedo \& Politi (2008) aplicaram este modelo para o mercado de leite. Goodwin \& Harper (1999) utilizaram este modelo no estudo do mercado da carne suína nos Estados Unidos. Já Bakucs et al. (2007) e Worth (1999) analisaram a transmissão de preços para o mercado de vegetais para a Hungria e Estados Unidos, respectivamente.

Um estudo que se destaca dentro desta literatura é o de Capps-Jr \& Sherwell (2007), por abordar o modelo de Houck através do modelo econométrico de correção de erros (MCE). Partindo da ideia de que o modelo original de Houck 
não levou em consideração as propriedades das séries temporais, esses autores propuseram a utilização do MCE, que capta a existência de cointegração (ECT) entre os dados. Se as séries de preços forem cointegradas, o vetor de cointegração representará a duração dos atrasos na transmissão de preços. A formulação de Capps \& Sherwell consiste em:

$$
\begin{aligned}
\Delta P_{v t}=\beta_{0} & +\sum_{i=1}^{P_{1}} \beta_{3 i} \Delta P_{v t-i}+\sum_{i=0}^{P_{2}} \beta_{4 i}^{+} \Delta P_{p t-i}^{+}+\sum_{i=0}^{P_{3}} \beta_{4 i}^{-} \Delta P_{p t-i}^{-} \\
& +\beta_{2}^{+} E C T_{t-1}^{+}+\beta_{2}^{-} E C T_{t-1}^{-}+v_{t}
\end{aligned}
$$

A equação (3) é semelhante ao modelo de Houck dado pela equação (1), com a adição de três termos: $\sum_{i=1}^{P_{1}} \beta_{3 i} \Delta P_{v t-i} ; \beta_{2}^{+} E C T_{t-1}^{+} ; \beta_{2}^{-} E C T_{t-1}^{-}$. O sobrescrito $P 1$ indica a defasagem de $\Delta P_{v t}, P 2$ é semelhante a $M 1$ e $P 3$ é semelhante a M2. A simetria de preços é testada por um teste $F$ conjunto, no qual se testam tanto os parâmetros do vetor de cointegração quanto os que estão fora, conforme a seguinte hipótese nula:

$$
H_{0}: \sum_{i=0}^{P_{2}} \beta_{4 i}^{+}=\sum_{i=0}^{P_{3}} \beta_{4 i}^{-} \text {e } \beta_{2}^{+}=\beta_{2}^{-}
$$

O enfoque representado pelas equações (3) e (4) se aplica ao caso bivariado. Para o caso multivariado, o ideal é que na presença de cointegração, se estime um vetor de correção de erros (VEC) com a seguinte especificação:

$$
\Delta P_{s t}=\gamma_{s}+\theta_{s} \rho_{s}^{\prime} P_{s t-1}+\sum_{i=1}^{p-1} \Gamma_{s i} \Delta P_{s t-i}+u_{s t}
$$

em que $P_{s t}^{\prime}=\left[S D C_{t} S A C_{t} V P_{s t}\right]^{\prime}$ é um vetor transposto de variáveis; $S D C_{t}=$ $\sum_{i=1}^{T} \Delta P_{a t-i}^{-}$é a soma dos decréscimos de preços no segmento atacadista; $S A C_{t}=$ $\sum_{i=1}^{T} \Delta P_{a t-i}^{+}$é a soma dos acréscimos de preços no segmento atacadista; $V P_{s t}=$ $\Delta P_{s t}$ é a variação de preços reais recebidos no segmento $s$ (onde $s$ é igual a 1 se produtor ou 0 se varejo); $\theta_{s} \rho_{s}^{\prime}$ é a matriz de cointegração, em que $\theta_{s}$ é um vetor $(3 \times 1)$ com os coeficientes de ajustamento e $\rho_{s}^{\prime}$ é um vetor $(1 \times 3)$ com os parâmetros de cointegração; $\Gamma_{s i}$ é a matriz $(3 \times 3)$ com os coeficientes da parte autorregressiva estimada (VAR); $\gamma_{s}$ é o vetor $(3 \times 1)$ com as constantes e $u_{s t}$ é o vetor $(3 T \times 1)$ com os termos de erros aleatórios. A assimetria de preços no longo prazo, nesse caso, é verificada pelo teste de Wald, no qual são testados se os parâmetros de cointegração relativos ao acréscimo e ao decréscimo de preços são iguais, isto é, se há simetria na transmissão de preços no longo prazo.

Os modelos estimados neste artigo seguem a estrutura mostrada na equação (5) e são uma forma de se trabalhar com o modelo de Houck através do Modelo Vetorial de Correção de Erros (VEC), que é uma extensão do Modelo de Correção de Erros elaborado no estudo de Capps-Jr \& Sherwell (2007). O modelo original proposto por Houck considerou como variável dependente as variações absolutas nos preços e, dessa forma, o modelo VEC aplicado aos dados de carne bovina não estabelece exatamente as mesmas relações entre as variáveis propostas por Houck. Entretanto, como apontam Cramon-Taubadel \& Fahlbusch (1994) e Meyer \& Cramon-Taubadel (2004), existe um potencial 
para uma regressão espúria em testes de simetria como do modelo original de Houck, quando são estimados sem levar em conta a possibilidade das séries de preços serem não-estacionárias. Portanto, a escolha do VEC se justifica ao analisar a estacionariedade das séries de preços. Neste artigo são estimados dois modelos visando verificar se existem simetrias na transmissão de preços do segmento atacadista para os produtores e para os varejistas. Assim, consideram-se as relações de determinação de preços entre atacado-produtor e atacado-varejo. A próxima seção descreve as características e os procedimentos metodológicos para a estimação desses modelos.

\subsection{Procedimentos metodológicos}

Para identificar a modelagem mais apropriada das séries temporais utilizadas, foram realizados os testes de identificação de raiz unitária e de cointegração. Seguindo procedimento indicado por Enders (1995), utilizou-se neste trabalho o teste de Dickey-Fuller Aumentado (ADF) para cada série do vetor $P^{\prime}{ }_{s t}=\left[\begin{array}{llll}S D C_{t} & S A C_{t} & V P_{s t}\end{array}\right]^{\prime}$, implementado por meio do software JMulti.

Para verificar se as séries são cointegradas, foi utilizado o procedimento de Johansen (1988). Conforme Lütkepohl (2007), o teste de cointegração de Johansen utilizou o teste de traço $\lambda_{t r}(r)$, o qual indica o número de vetores de cointegração do modelo. Se verificada a presença de um vetor de cointegração, estima-se o modelo VEC $(1,1)$, sendo que o número de defasagens no modelo foi escolhido com base no critério de Schwarz (SC).

Conforme dito anteriormente, este trabalho estima dois modelos para a cadeia da carne bovina, englobando os três níveis de mercado: produtor, atacado e varejo. O primeiro modelo, doravante referido como modelo AP, separa as variações no preço real praticado no atacado $\left(P A_{t}\right)$ em duas variáveis explicativas: uma variável para acréscimo e outra variável para decréscimo de preço; a terceira variável deste modelo é a variação dos preços reais pago ao produtor, conforme mostra a equação (6):

$$
\left(\begin{array}{c}
\Delta S D C_{t} \\
\Delta S A C_{t} \\
\Delta V P_{p t}
\end{array}\right)=\theta_{\mathbf{1}} \rho_{\mathbf{1}}^{\prime}\left(\begin{array}{c}
S D C_{t-1} \\
S A C_{t-1} \\
V P_{p t-1}
\end{array}\right)+\Gamma_{\mathbf{1 1}}\left(\begin{array}{c}
\Delta S D C_{t-1} \\
\Delta S A C_{t-1} \\
\Delta V P_{p t-1}
\end{array}\right)+\gamma_{\mathbf{1 1}}+u_{11 t}
$$

$S A C_{t}$ representa os acréscimos de preços reais praticados no atacado, e $S A C_{t}=\sum_{i=1}^{T}\left(P A_{t}-P A_{t-1}\right)$, para $P A_{t}>P A_{t-1}$, caso contrário igual a zero. $S D C_{t}$ representa os decréscimos de preços praticados no atacado, e $S D C_{t}=$ $\sum_{i=1}^{T}\left(P A_{t}-P A_{t-1}\right)$, para $P A_{t}<P A_{t-1}$, caso contrário igual a zero. $V P_{p t}$ representa as variações absolutas mensais do preço real pago ao produtor em relação ao preço inicial, sendo $V P_{p t}=P P_{t}-P P_{0}$. Os outros termos da equação (6) são: $\theta_{1} \rho_{1}^{\prime}$, que representa a matriz de cointegração do Modelo AP atacado/produtor, em que $\theta_{1}$ é um vetor $(3 \times 1)$ com os coeficientes de ajustamento e $\rho_{1}^{\prime}$ é um vetor $(1 \times 3)$ com os parâmetros de cointegração; $\Gamma_{11}$, a matriz $(3 \times 3)$ com os coeficientes da parte autorregressiva estimada (VAR); $\gamma_{11}$, o vetor $(3 \times 1)$ com as constantes estimadas para o modelo; $u_{11 t}$, o vetor $(3 T \times 1)$ com os termos de erro; e $t$, o tempo em meses.

Já o segundo modelo, denominado modelo AV, relaciona os acréscimos e decréscimos de preços reais praticados no atacado e as variações de preços no varejo. A equação (7) representa este modelo: 


$$
\left(\begin{array}{c}
\Delta S D C_{t} \\
\Delta S A C_{t} \\
\Delta V P_{v t}
\end{array}\right)=\theta_{2} \rho_{2}^{\prime}\left(\begin{array}{c}
S D C_{t-1} \\
S A C_{t-1} \\
V P_{v t-1}
\end{array}\right)+\Gamma_{21}\left(\begin{array}{c}
\Delta S D C_{t-1} \\
\Delta S A C_{t-1} \\
\Delta V P_{v t-1}
\end{array}\right)+\gamma_{21}+u_{22 t}
$$

Neste caso, $V P_{v t}$ são as variações absolutas mensais dos preços reais no varejo em relação ao preço inicial, representadas por $V P_{v t}=P_{v t}-P_{v 0}$. Assim como no primeiro modelo, $\theta_{2} \rho_{2}^{\prime}$ representa o vetor de cointegração do Modelo $\mathrm{AV}$, em que $\theta_{2}$ é um vetor $(3 \times 1)$ com os coeficientes de ajustamento e $\rho_{2}^{\prime}$ é um vetor $(1 \times 3)$ com os parâmetros de cointegração. Os outros termos da equação (7) são: $\Gamma_{21}$, a matriz $(3 \times 3)$ com os coeficientes da parte autoregressiva estimada; $\gamma_{21}$, o vetor $(3 \times 1)$ com as constantes estimadas para o modelo; $u_{22 t}, \mathrm{o}$ vetor $(3 T \times 1)$ com os termos de erro; e $t$, o tempo em meses.

As variações dos preços reais no varejo $\left(V P_{v t}\right)$ e dos preços reais pagos ao produtor $\left(V P_{p t}\right)$ foram construídas a partir das variações absolutas mensais dos mesmos em relação ao preço inicial, ou seja, as variações mensais em termos absolutos acumuladas no decorrer do tempo. As variáveis "acréscimos" e "decréscimos" dos preços reais praticados no atacado $\left(S A C_{t} ; S D C_{t}\right)$ foram obtidas separadamente a partir do somatório das diferenças do aumento (ou da diminuição) do preço de um mês em relação ao mês anterior. Quando há aumento, só a variável de acréscimo é alterada, quando há uma diminuição, apenas a variável decréscimo se altera. Este é justamente o procedimento desenvolvido por Houck, sendo que os preços reais foram transformados em logaritmos naturais para que os resultados dos modelos estimados forneçam as elasticidades de transmissão de preços de forma direta (Aguiar \& Santana 2002).

Os resultados dos modelos são analisados em três aspectos: simetria, intensidade (elasticidades) e velocidade. Considerando que seja encontrado um vetor de cointegração entre as variáveis para os dois modelos, há a comprovação de que de fato existe uma relação de longo prazo entre as variáveis de cada um dos modelos AP e AV.

Com o vetor de cointegração, pode-se analisar a simetria e as elasticidades de transmissão de preços. A simetria de preços ocorrerá se as séries decompostas de aumento e diminuição de preços no atacado apresentarem o mesmo grau de influência sobre os preços pagos ao produtor (modelo AP) ou sobre o preço recebido no varejo (modelo AV). Ou seja, considerando o modelo $\mathrm{AP}$, o aumento e a diminuição do preço praticado pelo atacado terão o mesmo poder de influenciar o preço pago ao produtor no longo prazo se os dois primeiros parâmetros de cointegração (relativos ao decréscimo e acréscimo no vetor $\rho_{1}^{\prime}$, respectivamente) forem iguais. Caso o parâmetro de cointegração relativo ao acréscimo for maior que o relativo ao decréscimo, a transmissão de acréscimo de preços do atacado ao produtor é maior que a transmissão de decréscimo, o que não é consistente com a estrutura de concorrência perfeita (Houck 1977). As elasticidades de transmissão de preços de longo prazo também são analisadas e, para testar a simetria na transmissão de preços no longo prazo, utiliza-se o teste de Wald sobre os parâmetros encontrados nos vetores de cointegração $\left(\rho_{s}^{\prime}\right)$, cujas hipóteses nulas são:

$$
\begin{aligned}
& \text { Para o Modelo AP: } H_{0}: \rho_{11}^{\prime}=\rho_{12}^{\prime} \\
& \text { Para o Modelo AV: } H_{0}: \rho_{21}^{\prime}=\rho_{22}^{\prime}
\end{aligned}
$$


Se $H_{0}$ for rejeitada, não se comprova estatisticamente a simetria na transmissão de preços do atacado para o produtor (Modelo AP) e/ou varejo (Modelo AV).

As funções impulso e resposta dos dois modelos permitem analisar a simetria de curto prazo na transmissão de preços, bem como permitem inferir sobre a velocidade de transmissão do aumento e da redução de preços. A decomposição da variância do erro de previsão contribui para identificar qual variável afeta mais a variância do erro de previsão das variações de preços reais no nível de produtor e de varejo, respectivamente nos modelos AP e AV.

\subsection{Fonte de dados e variáveis}

Para o cálculo das margens de comercialização e para estimar os modelos, são necessárias séries de preços para os diferentes níveis de comercialização da cadeia produtiva de pecuária de corte, produtor, atacado e varejo. Todos as séries de preços usadas têm periodicidade mensal entre janeiro de 2007 e novembro de 2013 e foram deflacionadas pelo Índice de Preço ao Consumidor (IPC).

As variáveis IPC e preço praticado no atacado foram obtidas no IPEADATA (2014). Essa última variável se refere ao preço médio no atacado de bovinos traseiro em São Paulo em $\mathrm{R} \$ / \mathrm{kg}$. Os demais preços, do varejo e do produtor, foram compatibilizados ao preço do atacado. Optou-se, então, pelo cálculo do preço da parte traseira dos bovinos em $\mathrm{R} \$ / \mathrm{kg}$.

No caso do preço do produtor, foi necessário calcular a participação do corte traseiro do bovino no valor do atacado (PCTVA). Essa participação é calculada pela equação (9).

PCTVA $=\frac{p a(\text { traseiro })}{\text { pa(traseiro })+p a(\text { dianteiro })+p a(\text { ponta de agulha })+p a(\text { miúdos })}$

em que pa(traseiro), pa(dianteiro), pa(ponta de agulha), pa(miúdos) são os preços médios de venda no mercado atacadista de cada corte na região metropolitana de São Paulo, obtidos no Instituto de Economia Agrícola ${ }^{4}$ (IEA 2014a).

Primeiramente, é necessário realizar a conversão do preço recebido pelo produtor no estado de São Paulo de R \$/arroba de carcaça (IEA 2014b) para $\mathrm{R} \$ / \mathrm{kg}^{5}$. Então, o preço do produtor foi obtido pela multiplicação da parcela do traseiro no valor do atacado com o preço do produtor convertido em $\mathrm{R} \$ / \mathrm{kg}$.

No caso do preço no varejo, o traseiro bovino corresponde aos cortes: alcatra, capa de filé, contrafilé, coxão duro, coxão mole, filé mignon, lagarto, patinho e músculo. Então o preço do varejo é o somatório dos preços médios de cada corte no varejo na capital São Paulo (IEA 2014c), sendo que cada preço é ponderado pelo rendimento de cada corte sobre a carcaça resfriada conforme Tabela 1.

\footnotetext{
${ }^{4}$ Segundo IEA (2014a), para o cálculo do preço da carne bovina no atacado, adotou-se a relação de quartos da carcaça: traseiro $=48 \%$, dianteiro $=39 \%$ e ponta de agulha $=13 \%$, que são os mais comumente relatados na literatura.

${ }^{5}$ Essa conversão foi realizada considerando que a proporção do corte da carcaça é de 229,62 kg (Boletim Pecuário 2014) o que corresponde a 15,31 arrobas (CEPEA 2014).
} 
Tabela 1: Rendimento da carne bovina resfriada para corte traseiro com osso

\begin{tabular}{lcc}
\hline Descrição do tipo de carne considerada & $\begin{array}{c}\text { Proporção de } \\
\text { corte em kg }\end{array}$ & $\begin{array}{c}\text { Rendimento } \\
\text { \% }\end{array}$ \\
\hline Detalhes de rendimentos da carcaça resfriada ${ }^{(1)}$ & 229,62 & $\mathbf{1 , 0 0}$ \\
\hline Rendimento do traseiro especial & $\mathbf{1 1 0 , 2 2}$ & $\mathbf{0 , 4 8}$ \\
\hline Filé & 8,04 & 0,04 \\
Contrafilé & 26,41 & 0,12 \\
Capa e aba & 6,43 & 0,03 \\
Alcatra & 15,15 & 0,07 \\
Patinho & 34,90 & 0,15 \\
Coxão duro & 19,98 & 0,09 \\
Coxão mole & 29,85 & 0,13 \\
Lagarto & 8,27 & 0,04 \\
Músculo & 12,63 & 0,06 \\
Retalho & 5,74 & 0,03 \\
Gordura & 16,99 & 0,07 \\
Ossos & 43,63 & 0,19 \\
\hline
\end{tabular}

Nota: (1) simulado para um animal com peso de $430 \mathrm{~kg}$

Fonte: Elaborado com dados disponíveis em Boletim Pecuário (2014).

\section{Resultados e Discussão}

A discussão dos resultados está dividida em cinco partes: modelos estimados; elasticidades de transmissão de preços; simetria/assimetria no repasse de preços no longo prazo; simetria/assimetria no repasse de preços no curto prazo; e, margens de comercialização.

\subsection{Modelos estimados}

Primeiramente foram testadas as condições de estacionariedade das séries por meio do teste $\mathrm{ADF}$ que tem por hipótese nula que as séries possuem raiz unitária, ou seja, as séries não são estacionárias. A partir da metodologia de Enders (1995), foram testadas três variações de modelo para cada variável: com constante e tendência; com constante e sem tendência; e sem constante e sem tendência ${ }^{6}$. Para as séries em nível, todos os valores estimados foram maiores que os valores críticos ao nível de significância de até $1 \%$. Como o teste ADF é unicaudal à esquerda, isso implica que não houve rejeição da hipótese nula e a série em nível não é estacionária. Para as séries diferenciadas há estacionariedade, uma vez que os valores calculados são menores que os valores críticos ao nível de significância de até $1 \%$. Dessa forma, conclui-se que as séries são integradas de ordem um [I(1)].

Para verificar a existência de relações de cointegração entre as séries foi realizado o teste de cointegração de Johansen - teste do traço. Na especificação desse teste usou-se o critério de Schwarz. De acordo com o teste do traço ${ }^{7}$, foi possível rejeitar a hipótese nula de que não há equilíbrio de longo prazo entre as variáveis para os dois modelos. Os resultados do teste de cointegração de Johansen sugerem, através do teste do traço, a existência de um vetor de cointegração para cada modelo, ao nível de significância de 5\%. Portanto, existem relações de longo prazo nas variações de preços reais da carne bovina entre o atacado e produtor e entre o atacado e varejo. Isso mostra que há

\footnotetext{
${ }^{6}$ Os resultados do teste ADF para a série em nível e para a série diferenciada se encontram no Apêndice A.

${ }^{7}$ Os resultados do teste do traço estão no Apêndice B.
} 
impactos de longo prazo das mudanças dos preços reais praticados no atacado sobre os preços pagos ao produtor e cobrados no varejo.

A partir dos resultados do teste de cointegração, foi possível estimar um VEC $(1,1)$ para os Modelos AP e AV, lembrando que o Modelo AP analisa como as variações de preços no nível do atacado impactam o preço do produtor (equação 10) e o Modelo AV analisa como as variações de preços no nível do atacado impactam o preço no varejo (equação 11$)^{8}$.

$$
\begin{aligned}
& \left(\begin{array}{c}
\Delta S D C_{t} \\
\Delta S A C_{t} \\
\Delta V P_{p t}
\end{array}\right)=\left[\begin{array}{c}
-0,274^{*} \\
-0,164^{* *} \\
-0,199^{* *}
\end{array}\right]\left[\begin{array}{lll}
1,000 & 0,942^{*} & -0,641^{*}
\end{array}\right]\left(\begin{array}{c}
S D C_{t-1} \\
S A C_{t-1} \\
V P_{p t-1}
\end{array}\right) \\
& +\left[\begin{array}{ccc}
0,137^{n s} & 0,075^{n s} & 0,054^{n s} \\
0,347^{* *} & -0,102^{n s} & 0,179^{* * *} \\
0,681^{*} & 0,298^{* * *} & -0,037^{n s}
\end{array}\right]\left(\begin{array}{c}
\Delta S D C_{t-1} \\
\Delta S A C_{t-1} \\
\Delta V P_{p t-1}
\end{array}\right)+\left[\begin{array}{c}
-0,012^{*} \\
0,031^{*} \\
0,012^{* *}
\end{array}\right] \\
& \left(\begin{array}{c}
\Delta S D C_{t} \\
\Delta S A C_{t} \\
\Delta V P_{v t}
\end{array}\right)=\left[\begin{array}{c}
-0,256^{*} \\
-0,113^{* * *} \\
0,061^{n s}
\end{array}\right]\left[\begin{array}{lll}
1,000 & 1,007^{*} & -0,834^{*}
\end{array}\right]\left(\begin{array}{c}
S D C_{t-1} \\
S A C_{t-1} \\
V P_{v t-1}
\end{array}\right) \\
& +\left[\begin{array}{ccc}
0,113^{n s} & 0,112^{n s} & 0,208 * \\
0,346^{* *} & -0,057^{n s} & 0,269^{*} \\
0,337^{* *} & 0,255^{* * *} & -0,049^{n s}
\end{array}\right]\left(\begin{array}{c}
\Delta S D C_{t-1} \\
\Delta S A C_{t-1} \\
\Delta V P_{v t-1}
\end{array}\right)+\left[\begin{array}{c}
-0,007^{* *} \\
0,031^{*} \\
0,003^{n s}
\end{array}\right]
\end{aligned}
$$

A estabilidade do modelo VEC requer que os autovalores encontrados estejam fora do círculo unitário. Todos os autovalores encontrados estão fora do círculo unitário, ou seja, os modelos VEC são estáveis ${ }^{9}$. É importante observar que a especificação do modelo requer a imposição de 2 raízes unitárias (número de variáveis menos o número relações de cointegração). Os modelos VEC escolhidos apresentaram os melhores desempenhos em relação à autocorrelação (ausência de autocorrelação dos resíduos), o que se observa por meio do teste $L M^{10}$. A hipótese nula do teste é a ausência de correlação serial, ou seja, o ideal é não rejeitar essa hipótese para que o modelo esteja bem especificado. Para os modelos estimados, não se rejeita a hipótese nula ao nível de significância de 5\%, o que indica não haver presença de autocorrelação no vetor de erros dos modelos estimados.

\subsection{Elasticidades de transmissão de preços}

A Tabela 2 mostra as estimativas dos coeficientes de longo prazo dos Modelos AP e AV estimados. Em relação ao Modelo AP, no longo prazo, se a soma de decréscimos de preços reais no atacado atingir $1 \%$, a variação média nos preços reais pagos ao produtor irá reduzir em $1,56 \%$, calculado pela razão entre as estimativas de coeficientes de longo prazo de $S D C_{t}$ por $V P_{p t}$. Por outro lado, se a soma de acréscimos de preços no atacado se elevar em $1 \%$ a variação do preço real pago ao produtor irá aumentar 1,46\%, calculado pela razão entre as estimativas de coeficientes de longo prazo de $S A C_{t}$ por $V P_{p t}$. Os desequilíbrios no preço pago ao produtor são corrigidos a uma taxa de

\footnotetext{
${ }^{8}$ As Estatísticas $t$ estão no Apêndice C.

${ }^{9}$ Resultados do teste de estabilidade dos Modelos no Apêndice D.

${ }^{10}$ Para as estatísticas do Teste LM de Autocorrelação Serial nos Resíduos ver Apêndice E.
} 
0,199\% em cada período, ou seja, para que o preço pago ao produtor retorne ao equilíbrio o horizonte temporal é de aproximadamente 5 meses.

Tabela 2: Estimativas dos coeficientes de longo prazo dos Modelos Vetoriais de Correção de Erro (VEC)

\begin{tabular}{cccc}
\hline & Variáveis & $\begin{array}{c}\text { Estimativas dos coeficientes } \\
\text { de ajustamento }(\theta)\end{array}$ & $\begin{array}{c}\text { Estimativas dos parâmetros } \\
\text { de longo prazo }(\rho)\end{array}$ \\
\hline \multirow{2}{*}{ Modelo } & $S D C_{t}$ & $-0,274^{*}$ & 1,000 \\
AP & $S A C_{t}$ & $-0,164^{* *}$ & $0,942^{*}$ \\
& $V P_{p t}$ & $-0,199^{* *}$ & $-0,641^{*}$ \\
\hline \multirow{2}{*}{ Modelo } & $S D C_{t}$ & $-0,256^{*}$ & 1,000 \\
AV & $S A C_{t}$ & $-0,113^{* * *}$ & $1,007^{*}$ \\
\hline \multicolumn{2}{l}{ Fonte: Elaborado pelos autores. Legenda: $\left(^{*}\right)$ significativo a $1 \% ;\left(^{* *}\right)$}
\end{tabular}

Para o Modelo AV, no longo prazo a soma de decréscimos de preços reais de $1 \%$ reduz a variação do preço real do varejo em 1,19\%. Por ouro lado, a soma de acréscimos de preços reais no atacado de $1 \%$ aumenta a variação do preço real no varejo em 1,20\%. Quanto aos desequilíbrios no preço do varejo não foi possível inferir sobre a taxa de ajuste temporal, pois a variável $V P_{v t}$ apresentou-se fracamente exógena, sendo o coeficiente de ajustamento $(0,061 \%)$ não significativo.

\subsection{Repasse de preços no longo prazo}

O teste de Wald indica se há realmente simetria de preço nos modelos no longo prazo. A hipótese nula deste teste é se o parâmetro de cointegração para o acréscimo é igual ao do decréscimo. Portanto, testa-se estatisticamente se $0,942=1$ (Modelo AP: $H_{0}: \rho^{\prime}{ }_{11}=\rho_{12}^{\prime}$ ) e se; $1,007=1$ (Modelo AV: $H_{0}$ : $\rho_{21}^{\prime}=\rho_{22}^{\prime}$ ). Se houver rejeição da hipótese nula, a simetria de preços no longo prazo é refutada. A Tabela 3 mostra as estimativas desse teste.

Tabela 3: Resultados do teste de Wald para simetria na transmissão de preços

\begin{tabular}{lcc}
\hline & Estatística do teste & P-valor \\
\hline Modelo AP & 6,7983 & 0,0091 \\
\hline Modelo AV & 0,0661 & 0,7971 \\
\hline Fonte: Elaborado pelos autores.
\end{tabular}

Da análise da Tabela 3, pode-se verificar pelo teste de Wald que houve rejeição da hipótese nula para o Modelo AP ( $\mathrm{p}$-valor $=0,0091)$ e não rejeição da hipótese nula para o Modelo AV ( $\mathrm{p}$-valor $=0,7971$ ). Então, no longo prazo, há simetria na transmissão de preços reais entre atacado e varejo. Contudo, há assimetria na transmissão de preços reais entre atacado e produtor.

Esses resultados indicam que o atacado (frigorífico) possui algum poder barganha, principalmente no momento de se ajustar os preços reais pagos ao produtor. Porém, para com o segmento varejista esse fato não se verifica. Isto pode ser compreendido analisando-se as estruturas de mercado nos vários níveis da cadeia produtiva. Enquanto o setor varejista cada vez mais se consolida como um mercado oligopolista, formado por hiper e supermercados, 
formando uma estrutura tão concentrada quanto o setor frigorífico, a relação entre (poucos) frigoríficos e (muitos) pecuaristas caracteriza-se por assimetria de poder de mercado, que se reflete em assimetria na transmissão de preços.

\subsection{Repasse de preços no curto prazo}

As funções impulso-resposta (Figura 2) mostram ajustamentos temporários (no curto prazo) de preços nos níveis de produtor e varejo ao se mudarem aleatoriamente os preços no atacado.

Figura 2: Resposta das variações dos preços pagos ao produtor e no varejo a impulsos nos acréscimos e decréscimos de preços reais no atacado.

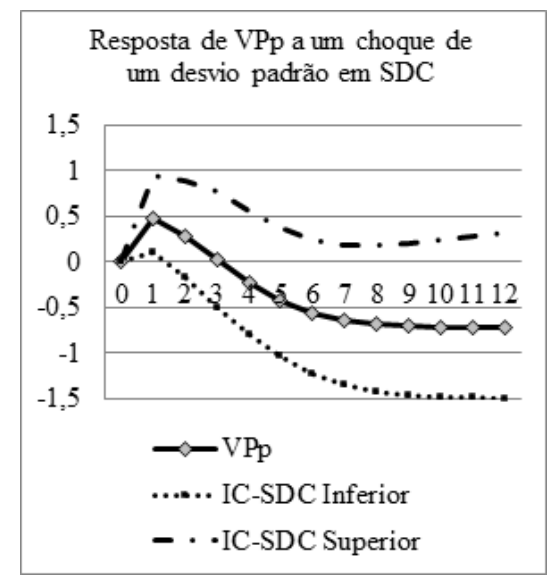

Resposta de VPv a um choque de um desvio padrão em SDC

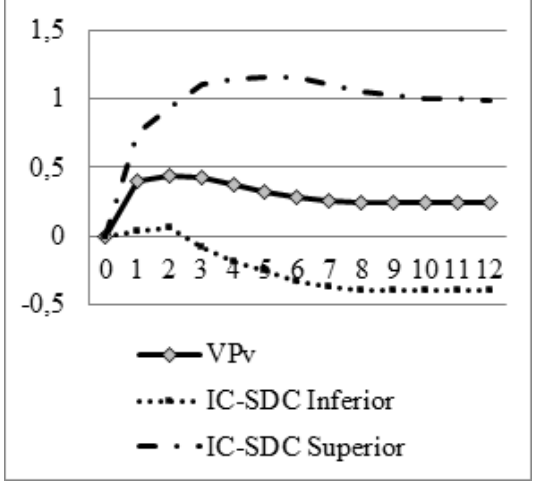

Fonte: Elaborado pelos autores.

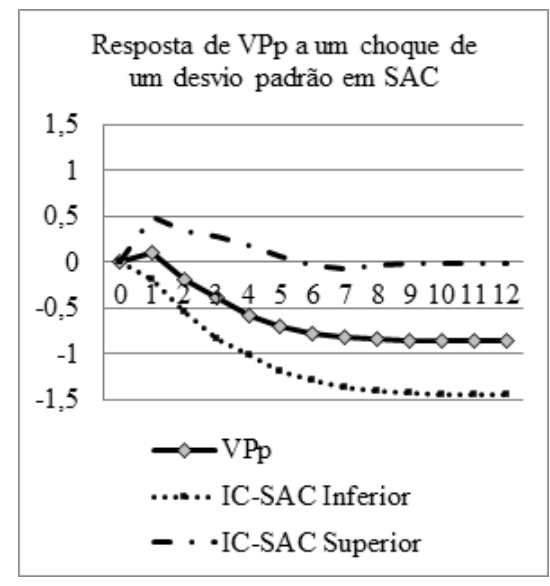

Resposta de VPv a um choque de um desvio padrão em SAC

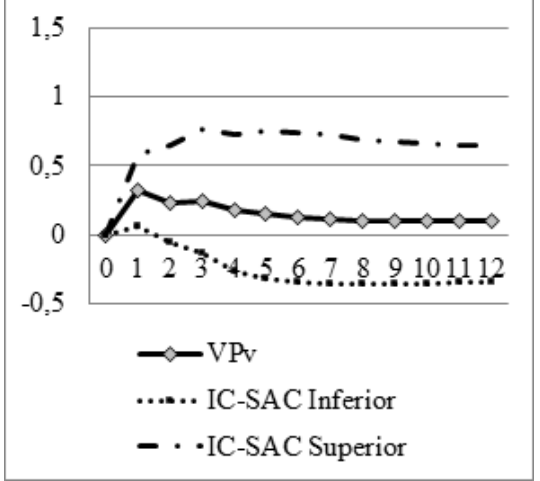

Para o Modelo AP, os decréscimos de preço no atacado foram significativos no primeiro mês após o choque, enquanto que os acréscimos não foram significativos nos seis primeiros períodos. Pode-se assim destacar a existência de certa rigidez de preços, já que no curto prazo não são repassados acréscimos de preços reais temporários do segmento atacado para os produtores, ocorrendo pequeno repasse de decréscimos reais de preços, fatos que mais uma vez se justificam pelo menor poder dos pecuaristas em relação ao frigorífico.

Para o Modelo AV pode-se perceber que acréscimos reais de preços no atacado foram significativos no primeiro mês após o choque, enquanto os de- 
créscimos foram significativos nos dois primeiros meses. Considerando que o repasse dos decréscimos de preços do atacado para o preço do varejo foi superior ao repasse dos acréscimos ainda no primeiro mês, pode-se inferir que o segmento atacado repassa, no curto prazo, decréscimos reais de preços mais intensamente do que acréscimos de preços ao varejo, sugerindo maior poder de barganha por parte do varejo em relação ao atacado. No longo prazo, esse cenário não ocorre e há simetria na transmissão de preços entre atacado e varejo, conforme já se viu.

Por meio da decomposição da variância do erro de previsão, os modelos estimados permitem avaliar a importância das variáveis para a realização de projeções. Trata-se de uma forma de mostrar quanto uma variável é importante para explicar o erro da previsão de outra.

Na Tabela 4, mostra-se a decomposição histórica da variância do erro de previsão para a variação do preço real da carne bovina pago ao produtor (Modelo AP) e para a variação do preço real da carne bovina recebido no varejo (Modelo AV) para um horizonte de 10 meses. A primeira coluna dessa tabela apresenta os períodos à frente que, nesse caso, estão expressos em meses, enquanto as demais se relacionam ao percentual da variância dos erros de previsão da variação do preço pago ao produtor ou da variação do preço do varejo que decorre de choques não antecipados sobre as demais variáveis endógenas contidas nos modelos - acréscimos de preço e decréscimos de preço no atacado. Detecta-se também que parte significativa da variância explicada (mais de $50 \%$ ) se deve à própria variável, indicando rigidez de preços.

Tabela 4: Decomposição da variância do erro de previsão da variação do preço pago ao produtor e da variação do preço cobrado no varejo

\begin{tabular}{c|ccc|ccc}
\hline \multirow{2}{*}{ Mês } & \multicolumn{3}{|c|}{ Modelo AP } & \multicolumn{3}{c}{ Modelo AV } \\
\cline { 2 - 7 } & \multicolumn{3}{|c|}{ Variáveis } & \multicolumn{3}{c}{ Variáveis } \\
\cline { 2 - 7 } & $V P_{p}$ & SAC & SDC & $V P_{v}$ & SAC & SDC \\
\hline 1 & $53 \%$ & $32 \%$ & $15 \%$ & $74 \%$ & $12 \%$ & $14 \%$ \\
2 & $43 \%$ & $30 \%$ & $27 \%$ & $54 \%$ & $19 \%$ & $27 \%$ \\
3 & $48 \%$ & $27 \%$ & $26 \%$ & $51 \%$ & $19 \%$ & $30 \%$ \\
4 & $54 \%$ & $24 \%$ & $22 \%$ & $51 \%$ & $19 \%$ & $31 \%$ \\
5 & $60 \%$ & $22 \%$ & $18 \%$ & $51 \%$ & $18 \%$ & $30 \%$ \\
6 & $65 \%$ & $19 \%$ & $16 \%$ & $52 \%$ & $18 \%$ & $30 \%$ \\
7 & $69 \%$ & $18 \%$ & $13 \%$ & $53 \%$ & $17 \%$ & $29 \%$ \\
8 & $72 \%$ & $16 \%$ & $12 \%$ & $54 \%$ & $17 \%$ & $29 \%$ \\
9 & $75 \%$ & $15 \%$ & $10 \%$ & $55 \%$ & $17 \%$ & $28 \%$ \\
10 & $77 \%$ & $14 \%$ & $9 \%$ & $56 \%$ & $17 \%$ & $28 \%$ \\
\hline
\end{tabular}

Fonte: Elaborado pelos autores.

Para o Modelo AP, observa-se que os acréscimos de preços reais no atacado explicam 32\% do erro de previsão das variações dos preços pagos ao produtor no primeiro mês, enquanto os decréscimos explicam 15\%. Apesar do ganho de importância dos decréscimos ao longo dos 10 meses após o choque, os acréscimos do preço do atacado são os que influenciam, principalmente, o erro de previsão do preço pago ao produtor. Quanto ao Modelo AV observa-se que durante os 10 meses após o choque, os decréscimos de preços no atacado influenciam mais o erro de previsão da variação de preço do varejo que os acréscimos. 


\subsection{Margens de Comercialização}

Por último, foram comparados os resultados obtidos nos dois modelos com as margens existentes para cada nível da cadeia de produção de carne bovina. A Figura 3 mostra a representação das margens dos produtores, atacado e varejo. Como é possível perceber pela Figura 3, períodos de aumento da margem de comercialização do atacado são marcados, respectivamente, por aumentos de menores proporções nas margens dos produtores. Esse resultado é coerente com o obtido pelo Modelo AP, ou seja, não há simetria no repasse de preços no longo prazo, confirmado pelo teste de Wald. Dessa forma, os aumentos de preço do atacado não são repassados integralmente aos produtores.

Figura 3: Margens de Comercialização.

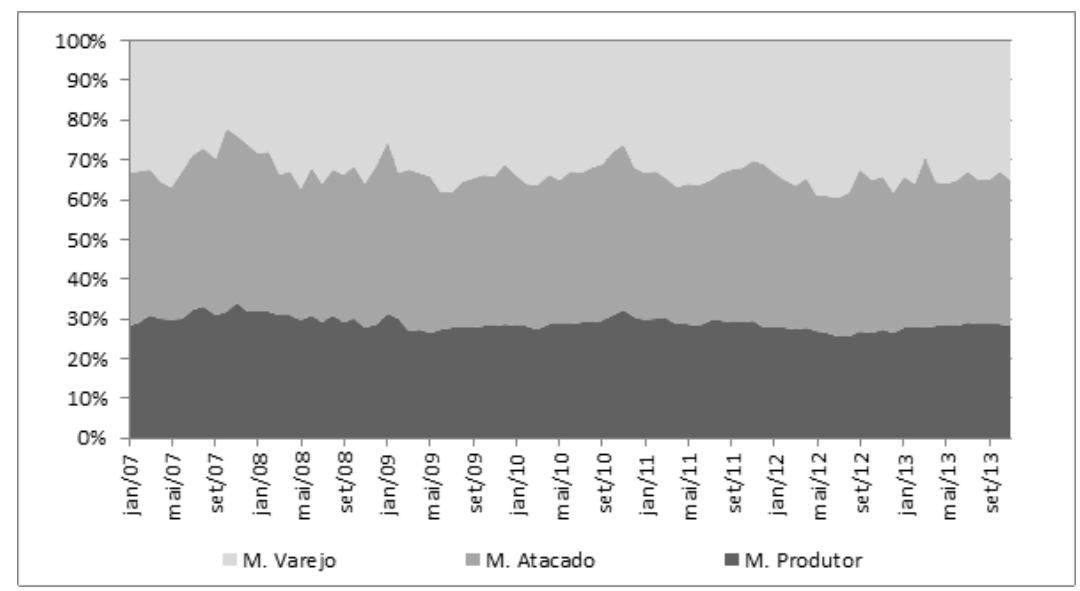

Fonte: Elaborado pelos autores.

Comparando as margens de comercialização do atacado em relação ao varejo observam-se períodos de elevação da margem do atacado são períodos de redução da margem no varejo, assim como períodos de redução da margem do atacado representam elevações nas margens do varejo.

\section{Conclusão}

Utilizando modelos VEC, o presente trabalho encontrou evidências de que o atacado (frigorífico) possui poder na negociação de preços junto aos produtores, mas que há um equilíbrio em sua relação com o varejo. No geral, aos pecuaristas são transmitidas mais intensamente as quedas do que os aumentos de preço dos frigoríficos, enquanto que aos varejistas transmitem-se simetricamente aumentos e quedas de preços nos frigoríficos. A explicação para este fenômeno remonta às estruturas de mercado, havendo maior equilíbrio de poder de mercado entre frigoríficos e varejistas (supermercados) - onde ambas as estruturas são oligopolistas, do que entre frigoríficos e pecuaristas.

Em termos de política pública, os resultados da pesquisa indicam que os órgãos de defesa da concorrência devem avaliar rigorosamente tanto os processos de concentração de mercado quanto as condutas exercidas pelos frigoríficos em relação aos pecuaristas, visando coibir abuso de poder de mercado. Quanto aos pecuaristas, a busca de negociações coletivas (por meio de associa- 
ções, cooperativas ou outras formas de cooperação) que aumentem seu poder de contraposição aos frigoríficos e a adoção de estratégias de hedging, principalmente com o uso de contratos futuros e de opções, surgem como alternativa de proteção em cenários de quedas de preços.

Destaca-se que assimetrias de preços praticadas de forma intensa e continuada entre elos de uma cadeia produtiva podem levar, em situações extremas, a uma redução significativa da margem lucro de um dos segmentos, sendo possível ocorrer até mesmo a saída de alguns agentes da atividade. A técnica aplicada nesse trabalho permite identificar padrões de repasse de preços entre os elos da cadeia de produção, sendo possível utilizá-la para acompanhamento de possíveis distorções, servindo, portanto, como instrumento adicional que pode ser utilizado por órgãos de defesa da concorrência.

No caso específico da relação frigoríficos-varejistas, como o método empregado nesta pesquisa permite separar os efeitos de curto dos de longo prazo, notou-se que, embora houvesse alguma assimetria no curto prazo, indicando que os varejistas conseguiriam transmitir mais intensamente os aumentos de preço dos frigoríficos, no longo prazo acréscimos e decréscimos são igualmente transmitidos. Isso sugere que os varejistas incorporam ganhos de curto prazo, mas que no longo prazo tal possibilidade de ganho desaparece. Podese dizer, assim, que o poder de barganha dos segmentos varejista e, especialmente, atacadista, é notoriamente maior que o poder dos produtores tanto por suas margens de comercialização quanto por suas transmissões de preços. No caso do varejo, há de se notar que o possível exercício de poder de mercado no curto prazo não se dá em relação aos frigoríficos, mas sim em relação aos consumidores finais.

O que se percebe ao analisar a literatura sobre os modelos de transmissão de preços é uma ausência de consenso em como tratar o modelo de Houck (1977), considerando as propriedades de séries temporais. Diante dessa ausência sobre o tratamento econométrico a ser dado à questão, o presente trabalho contribui ao propor uma forma de trabalhar com o modelo de Houck através do VEC. Dessa forma, a principal contribuição para a ciência econômica é desenvolver um modelo semelhante ao de Capps-Jr \& Sherwell (2007), mas que se aplica às relações entre três níveis de mercado. Ademais, contribui para a identificação e o acompanhamento de possível exercício de poder de mercado na cadeira produtiva de pecuária de corte do Brasil, uma questão que tem gerado grandes preocupações tanto para os agentes deste mercado como para o poder público.

\section{Referências Bibliográficas}

ABIEC (2018), 'Perfil da pecuária no brasil - relatório anual 2018', São Paulo: ABIEC. Disponível em: <http://www.abiec.com.br/Sumario.aspx>. Acesso em 18/10/2018.

Aguiar, D. R. D. (2000), 'Mensuração de poder de mercado por meio de dados de marcas comerciais: Modelos, limitações e aplicações', Revista de Economia Politica 20(3), 152-162.

Aguiar, D. R. D. (2012), 'Indicadores de poder de mercado baseados nos preços', $50^{\circ}$ Congresso da Sociedade Brasileira de Economia, Administração e Sociologia Rural, Vitória - ES. 
Aguiar, D. R. D. \& Figueiredo, A. M. A. (2011), 'Poder de Mercado no Varejo Alimentar: uma análise usando os preços do Estado de São Paulo', Revista de Economia e Sociologia Rural 49(4), 967-990.

Aguiar, D. R. D. \& Santana, J. A. (2002), 'Asymmetry in farm to retail price transmission: evidence from Brazil’, Agribusiness 18(1), 37-48.

Azevedo, P. F. \& Politi, R. B. (2008), 'Concorrência e estratégias de precificação no sistema agroindustrial do leite', Revista de Economia e Sociologia Rural 46(3), 767-802.

Bakucs, L. Z., Ferto, I. \& Szabó, G. G. (2007), 'Price transmission in the hungarian vegetable sector', Studies in Agricultural Economics 106, 23-40.

Boletim Pecuário (2014), 'Desmonte do bovino', Disponível em: < http://www.boletimpecuario.com.br/rendimentob.htm $>$. Acesso em: 08/01/2014.

Brasil (2014), 'Mapa, Ministério da Agricultura, Pecuária e Abastecimento (MAPA).', Disponível em <http://www.agricultura.gov.br>. Acesso em: 09/01/2014.

Brasil (2015), 'Projeções do agronegócio: Brasil 2014/2015 a 2024/2025 - projeções de longo prazo', Brasília: MAPA. Disponível em <http://www.agricultura.gov.br>. Acesso em: 07/01/2016.

CADE (2007), Conselho Administrativo de Defesa Econômica - Guia Prático do CADE: a defesa da concorrência no Brasil, 3 ed, São Paulo: CIEE.

Capps-Jr, O. \& Sherwell, P. (2007), 'Alternative Approaches in Detecting Asymmetry in Farm-Retail Price Transmission of Fluid Milk', Agribusiness 23(3), 313-331.

Carman, H. F. \& Sexton, R. J. (2005), 'Supermarket fluid milk pricing practices in the Western United States', Agribusiness 21, 509-530.

Carvalho, T. B. \& Zen, S. (2017), 'A cadeia de Pecuária de Corte no Brasil: evolução e tendências.', Revista IPecege 3(1), 85-99.

CEPEA (2014), 'Centro de Estudos Avançados em Economia Aplicada - Indicador Boi, Média Estado São Paulo', Disponível em: < http://cepea.esalq.usp.br/boi/>. Acesso em: 15/01/2014.

Cramon-Taubadel, S. (1998), 'Estimating asymmetric price transmission with the error correction representation: An application to the German pork market', European Review of Agricultural Economics 25, 1-18.

Cramon-Taubadel, S. \& Fahlbusch, S. (1994), 'Identifying asymmetric price transmission with error correction models', Poster Session EAAE European Seminar in Reading.

Enders, W. (1995), Applied Econometric Time Series, 1st ed, New York: Wiley.

Goodwin, B. K. \& Harper, D. C. (1999), 'Price transmission, threshold behavior, and asymmetric adjustment in the U.S. pork sector.', Paper presented at AABA Meetings, Nashville. 
Houck, J. P. (1977), 'An approach to specifying and estimating nonreversible functions.', American Journal of Agricultural Economics, Ames 59, 570-572.

IBGE (2018), 'Instituto Brasileiro de Geografia e Estatística. censo agropecuário 2017.', Disponível em: < https://sidra.ibge.gov.br>. Acesso em: $18 / 10 / 2018$.

IEA (2014a), 'Instituto de Economia Agrícola. carne bovina: comportamento dos preços em 2010.', Disponível em: <

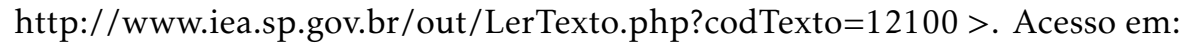
$12 / 11 / 2014$.

IEA (2014b), 'Instituto de Economia Agrícola. Preços Médios Mensais de Venda no Mercado Atacadista na Região Metropolitana de São Paulo.', Disponível em: < http://www.iea.sp.gov.br/out/bancodedados.html >. Acesso em: $15 / 01 / 2014$.

IEA (2014c), 'Instituto de Economia Agrícola. Preços Médios Mensais no Varejo na Capital.', Disponível em: < http://www.iea.sp.gov.br/out/bancodedados.html $>$. Acesso em: $15 / 01 / 2014$.

IPEADATA (2014), 'Instituto de Pesquisas Econômicas Aplicadas - base de dados macroeconômicos - IPC - geral - índice - Fundação Getulio Vargas, Conjuntura Econômica - IGP (FGV/Conj. Econ. - IGP).', Disponível em: $<$ www.ipeadata.gov.br>. Acesso em: 15/01/2014.

JBS (2018), 'Informação corporativa - histórico.', Disponível em: <http://jbss.infoinvest.com.br/static/ptb/historico.asp?idioma $=$ ptb $>$. Acesso em: 18/10/2018.

Johansen, S. (1988), 'Statistical analysis of cointegration vectors', Journal of Economic Dinamics and Control 12, 231-254.

Kinnucan, H. W. \& Foker, O. D. (1987), 'Asymmetry in farm-retail price transmission for major dairy products', American journal of agricultural economics 69(2), 285-292.

Lass, D. A. (2005), 'Asymmetric response of retail milk prices in the northeast revisited.', Agribusiness 21(4), 493-508.

Lütkepohl, H. (2007), New Introduction to Multiple Time Series Analysis, 2 ed, New York: Springer.

Marfrig (2018), 'Perfil corporativo e histórico', Disponível em: $<$ http://ri.marfrig.com.br/pt/grupo-marfrig/perfil-corporativo-ehistorico $>$. Acesso em: 18/10/2018.

Meyer, J. \& Cramon-Taubadel, S. (2004), 'Asymmetric price transmission: a survey.', Journal of Agricultural Economics 55(3), 581-611.

Minerva (2018), 'Sobre Minerva Foods - história', Disponível em: $<$ https://portal.minervafoods.com/sobre-minerva-foods $>$. Acesso em: $18 / 10 / 2018$. 
Moita, R. M. \& Goloni, L. A. (2010), 'Oligopsônio dos Frigoríficos: Uma Análise Empírica de Poder de Mercado', Rev. adm. contemp 18(6), 772-794.

Rodovalho, H. S. (2010), 'Estruturas de mercado, a integração vertical e as novas tecnologias aplicadas na pecuária de corte', Revista Saber Eletrônico $2,83-114$.

Santos, J. Z. D., Aguiar, D. R. D. \& Figueiredo, A. M. (2015), 'Assimetria na transmissão de preços e poder de mercado: o caso do mercado varejista de etanol no estado de São Paulo', Revista de Economia e Sociologia Rural 53(2), 195-210.

Urso, F. S. P. (2007), 'A cadeia da carne bovina no Brasil: uma análise de poder de mercado e teoria da informação', Fundação Getúlio Vargas .

Worth, T. (1999), 'The FOB retail price relationship for selected fresh vegetables', Economic Research Service/ USDA pp. 26-31. 


\section{Apêndice A}

Tabela A.1: Teste ADF para as variáveis utilizadas na construção dos modelos

\begin{tabular}{|c|c|c|c|c|c|}
\hline \multicolumn{6}{|c|}{ ADF-NÍVEL } \\
\hline \multirow{2}{*}{ Variáveis } & \multirow{2}{*}{$\begin{array}{c}\text { Termo } \\
\text { Determinístico }\end{array}$} & \multirow{2}{*}{ Estatística $\tau$} & \multicolumn{3}{|c|}{ Valor crítico } \\
\hline & & & $1 \%$ & $5 \%$ & $10 \%$ \\
\hline \multirow{3}{*}{$S A C_{t}$} & $\mathrm{C} / \mathrm{T}$ & $-2,3713$ & $-3,96$ & $-3,41$ & $-3,13$ \\
\hline & $\mathrm{C}$ & $-0,7961$ & $-3,43$ & $-2,86$ & $-2,57$ \\
\hline & - & 4,4802 & $-2,56$ & $-1,94$ & $-1,62$ \\
\hline \multirow{3}{*}{$S D C_{t}$} & $\mathrm{C} / \mathrm{T}$ & $-3,9258$ & $-3,96$ & $-3,41$ & $-3,13$ \\
\hline & C & 0,1879 & $-3,43$ & $-2,86$ & $-2,57$ \\
\hline & - & 4,9724 & $-2,56$ & $-1,94$ & $-1,62$ \\
\hline \multirow{3}{*}{$V P_{p t}$} & $\mathrm{C} / \mathrm{T}$ & $-3,0729$ & $-3,96$ & $-3,41$ & $-3,13$ \\
\hline & $\mathrm{C}$ & $-2,9528$ & $-3,43$ & $-2,86$ & $-2,57$ \\
\hline & - & $-0,4085$ & $-2,56$ & $-1,94$ & $-1,62$ \\
\hline \multirow{3}{*}{$V P v t$} & $\mathrm{C} / \mathrm{T}$ & $-1,9898$ & $-3,96$ & $-3,41$ & $-3,13$ \\
\hline & C & $-1,8766$ & $-3,43$ & $-2,86$ & $-2,57$ \\
\hline & - & 0,2014 & $-2,56$ & $-1,94$ & $-1,62$ \\
\hline \multicolumn{6}{|c|}{ ADF-1 ${ }^{a}$ Diferença } \\
\hline \multirow{2}{*}{ Variáveis } & \multirow{2}{*}{$\begin{array}{c}\text { Termo } \\
\text { Determinístico }\end{array}$} & \multirow{2}{*}{ Estatística $\tau$} & \multicolumn{3}{|c|}{ Valor crítico } \\
\hline & & & $1 \%$ & $5 \%$ & $10 \%$ \\
\hline \multirow{3}{*}{$S A C_{t}$} & $\mathrm{C} / \mathrm{T}$ & $-8,0165$ & $-3,96$ & $-3,41$ & $-3,13$ \\
\hline & $\mathrm{C}$ & $-8,0288$ & $-3,43$ & $-2,86$ & $-2,57$ \\
\hline & - & $-5,9987$ & $-2,56$ & $-1,94$ & $-1,62$ \\
\hline \multirow{3}{*}{$S D C_{t}$} & $\mathrm{C} / \mathrm{T}$ & $-7,8892$ & $-3,96$ & $-3,41$ & $-3,13$ \\
\hline & C & $-7,9166$ & $-3,43$ & $-2,86$ & $-2,57$ \\
\hline & - & $-5,8938$ & $-2,56$ & $-1,94$ & $-1,62$ \\
\hline \multirow{3}{*}{$V P_{p t}$} & $\mathrm{C} / \mathrm{T}$ & $-6,5604$ & $-3,96$ & $-3,41$ & $-3,13$ \\
\hline & $\mathrm{C}$ & $-6,5603$ & $-3,43$ & $-2,86$ & $-2,57$ \\
\hline & - & $-6,5442$ & $-2,56$ & $-1,94$ & $-1,62$ \\
\hline \multirow{3}{*}{$V P v t$} & $\mathrm{C} / \mathrm{T}$ & $-7,7156$ & $-3,96$ & $-3,41$ & $-3,13$ \\
\hline & $\mathrm{C}$ & $-7,6983$ & $-3,43$ & $-2,86$ & $-2,57$ \\
\hline & - & $-7,615$ & $-2,56$ & $-1,94$ & $-1,62$ \\
\hline
\end{tabular}

Fonte: Elaborado pelos autores.

Nota: C, T indica a presenta de constante $(\mathrm{C})$ e tendência $(\mathrm{T})$ na equação do teste de Raiz Unitária.

\section{Apêndice B}

Tabela B.1: Análise da Cointegração de Johansen Resultados do teste do traço

\begin{tabular}{l|c|c|c}
\hline & \multicolumn{3}{|c}{ Modelo AP } \\
\hline Hipótese nula & Estatística do traço & Valor crítico (5\%) & p-valor \\
\hline$r=0$ & 49,03 & 42,77 & 0,0096 \\
$r \leq 1$ & 21,88 & 25,73 & 0,1464 \\
$r \leq 2$ & 9,81 & 12,45 & 0,1384 \\
\hline & \multicolumn{3}{|c}{ Modelo AV } \\
\hline Hipótese nula & Estatística do traço & Valor crítico (5\%) & p-valor \\
\hline$r=0$ & 50,36 & 42,77 & 0,0065 \\
$r \leq 1$ & 17,08 & 25,73 & 0,417 \\
$r \leq 2$ & 6,33 & 12,45 & 0,4305 \\
\hline
\end{tabular}

Fonte: Elaborado pelos autores. 


\section{Apêndice C Estatísticas $t$ de Student dos Modelos Estimados}

$$
\begin{aligned}
& \left(\begin{array}{c}
\Delta S D C_{t} \\
\Delta S A C_{t} \\
\Delta V P_{p t}
\end{array}\right)=\left(\begin{array}{l}
-4,513 \\
-2,035 \\
-2,127
\end{array}\right)\left(\begin{array}{lll}
\cdots & 42,099 & -5,830
\end{array}\right)\left(\begin{array}{c}
S D C_{t-1} \\
S A C_{t-1} \\
V P_{p t-1}
\end{array}\right) \\
& +\left(\begin{array}{ccc}
1,221 & 0,638 & 0,611 \\
2,330 & -0,647 & 1,519 \\
3,957 & 1,637 & -0,268
\end{array}\right)\left(\begin{array}{c}
\Delta S D C_{t-1} \\
\Delta S A C_{t-1} \\
\Delta V P_{p t-1}
\end{array}\right)+\left(\begin{array}{c}
-2,946 \\
5,782 \\
1,985
\end{array}\right) \\
& \left(\begin{array}{c}
\Delta S D C_{t} \\
\Delta S A C_{t} \\
\Delta V P_{v t}
\end{array}\right)=\left(\begin{array}{c}
-4,633 \\
-1,494 \\
0,785
\end{array}\right)\left(\begin{array}{lll}
\cdots & 37,854 & -7,444
\end{array}\right)\left(\begin{array}{c}
S D C_{t-1} \\
S A C_{t-1} \\
V P_{v t-1}
\end{array}\right) \\
& +\left(\begin{array}{ccc}
1,072 & 1,099 & 2,626 \\
2,379 & -0,402 & 2,464 \\
2,251 & 1,763 & -0,436
\end{array}\right)\left(\begin{array}{c}
\Delta S D C_{t-1} \\
\Delta S A C_{t-1} \\
\Delta V P_{v t-1}
\end{array}\right)+\left(\begin{array}{c}
-1,820 \\
5,696 \\
0,445
\end{array}\right)
\end{aligned}
$$

Fonte: Elaborado pelos autores.

\section{Apêndice D}

Tabela D.1: Análise da Estabilidade dos Modelos

\begin{tabular}{c|c}
\hline Modelo AP & Modelo AV \\
\hline Módulo das raízes do polinômio característico & Módulo das raízes do polinômio característico \\
\hline 1,6866 & 1,6055 \\
1,6866 & 1,6055 \\
9,0655 & 5,3860 \\
3,0402 & 2,6705 \\
1,0000 & 1,0000 \\
1,0000 & 1,0000 \\
\hline
\end{tabular}

Fonte: Elaborado pelos autores.

\section{Apêndice $E$}

Tabela E.1: Teste de autocorrelação (LM)

\begin{tabular}{c|c|c|c|c|c}
\hline \multicolumn{2}{c|}{ Modelo AP } & \multicolumn{3}{c}{ Modelo AV } \\
\hline Defasagem & Estatística & p-valor & Defasagem & Estatística & p-valor \\
\hline 8 & 78,0618 & 0,2922 & 8 & 82,3677 & 0,1893 \\
\hline Fonte: Elaborado pelos autores.
\end{tabular}

